\title{
Work Engagement in Female Academics at an Open Distance Learning and a Contact University in South Africa - A Review and Critique
}

\author{
Adéle Bezuidenhout \\ Professor, University of South Africa \\ E-mail: bezuia@unisa.ac.za
}

Gerhard Bezuidenhout

Tutor, University of South Africa

Doi:10.5901/mjss.2014.v5n7p324

\begin{abstract}
This research focused on the work engagement as represented by the sub-dimensions of vigour, absorption and dedication in female academics at two universities in South Africa. An open distance learning (ODL) university, as well as a traditional contact university were targeted. A positive psychological paradigm perspective guided the research. A cross-sectional survey design was used. In total 187 permanently employed female academics at the two universities completed the survey. The findings included that the work engagement scores of the female academics were just above average. It is recommended that universities introduce a management strategy to facilitate, nurture and encourage the experience of work engagement among female academics and that these academics take personal responsibility for their own wellness. Furthermore, they need to act on the initial signs of decreasing work engagement, rather than dismissing it as mere fatigue or lack of energy.
\end{abstract}

Keywords: work engagement, female academics; wellness; vigour; absorption; dedication

\section{Introduction}

It is concerning to note that more than half of the world's population lacks enthusiasm and is not actively engaged with the world and in particular their own world of work (Seligman, 2002). Psychology as a research field is sometimes criticised for not focusing enough on the positive outcomes in the work environment (Diener, Suh, Lucas, \& Smith, 1999). Also in terms of studies on the female gender as such, various researchers identify the need for a more positive approach, focusing on the enhancement of health (Nelson, Burke, \& Michie, 2002; Simmons, 2000; Taylor, Klein, Lewis, Grunewald, Gurung, \& Updegraff, 2000). The question asked by many organisational psychology scholars is why certain workers can enthusiastically accomplish large amounts of work, while being fully engaged, without feeling exhausted. In addition, researchers have been studying the reason why female academics experience more stress symptoms than their male colleagues (Blix, Cruise, Mitchell, \& Blix, 1994).

The challenges faced by people in trying to cope with the "changing world of work" is a theme that is currently receiving a lot of research attention among scholars. The theme chosen for the $15^{\text {th }}$ Industrial and Organisational Psychology Conference in South Africa (Siopsa, 2013) was indeed "Making a difference in the future world of work". Stanz (2013) identifies the characteristics of the new world of work as globalisation and digital transformation, working remotely, changes in talent pools, "greening" and the impact of social media. In support of these, Furnham (2013) speculates on the role that psychology and, in particular, work psychology can play in supporting individuals to cope with the new and ever-changing world of work. Breed, Cilliers and Visser (2006) are of the opinion that the operationalisation of positive psychological constructs are used increasingly to explain how people cope with the rapidly changing world of work around them. The changing world of work in the context of this study entails the continuously changing landscape of the South African higher education (HE) system, for example the implications of the newly announced White Paper on Post School Education (Nzimande, 2014), the inability of the public HE system to absorb prospective students and the rise of the private HE system (Bezuidenhout, De Jager, \& Naidoo, 2013), increasing job demands, labour unrest, everincreasing class sizes and role conflict inhibiting the positive experience of work engagement. The constant transformation of the HE system results in the transformation of learning itself, as well as changes in the competencies and capacities that academics need to be successful in the current HE context (both in distance learning and in contact 
universities).

The results of this research will contribute towards the growing body of knowledge on the changing world of work, the salutogenic paradigm and positive organisational psychology in general. The main contribution of this study is to provide empirical evidence on the manifestation of work engagement and its sub-dimensions in this target group, and to make recommendations to both the individuals and the organisations on ways in which work engagement can be facilitated and encouraged within this context.

\section{Literature Review}

Both a definition, as well as a theoretical framework for work engagement is offered and previous research findings presented.

\subsection{Definition of work engagement}

Work engagement is defined differently by many scholars, varying in scope and depth, mainly because of the different viewpoints held by practitioners or consultants and scientific or academic scholars. For the purposes of this paper an academic approach is followed, as explained by Schaufeli (2012). Work engagement is defined as a positive, fulfilling, work-related state of mind that is characterised by vigour, dedication and absorption (Schaufeli \& Bakker, 2006:702). The three different but related dimensions are explained as follows:

Firstly, vigour refers to high levels of energy and resilience, the willingness to invest effort in one's job, not being easily fatigued and persistence in the face of difficulties (Bakker, Demerouti, \& Schaufeli, 2005; Gonzalez-Roma, Schaufeli, Bakker, \& Lloret, 2006; Schaufeli, 2004). Secondly, dedication refers to a strong involvement in one's work, accompanied by feelings of enthusiasm and significance, inspiration and a sense of pride (Langelaan, Bakker, Van Doornen, \& Schaufeli, 2006; Schaufeli, 2004).

Thirdly, absorption was found to be another constituting element of work engagement (Bakker et al., 2005). Absorption refers to a pleasant state of being happily and totally engrossed in one's work, which is characterised by time passing quickly and being unable to detach oneself from the job (Langelaan et al., 2006; Schaufeli, 2004). Absorption is also referred to as "flow", a state of optimal experience (Csikszentmihalyi, 1990).

Holistically considered, vigour and dedication are considered the core dimensions of work engagement, and absorption was found to be a relevant aspect of work engagement after a number of interviews were conducted (Bakker et al., 2005; Schaufeli \& Bakker, 2001, 2004). A lot of work has been done on the construct over the past decade, as explained in the next section.

\subsection{Development of the theoretical framework}

The term "engagement" is first found in business contexts during the 1990s, after which scientific attention was paid from 2000 onwards to it in academia (Schaufeli, 2012). Research on the work engagement concept has taken two separate but related paths (Storm, 2002). Maslach and Leiter (1997) describe work engagement as being characterised by energy, involvement and efficacy, which are considered the direct opposites of the three burnout dimensions, namely exhaustion, cynicism and lack of professional efficacy, respectively. In contrast to burnout, focusing on work engagement means focusing on the energy, involvement and effectiveness that employees, in this case female academics, bring to the job and develop through their jobs. They believe that a focus on work engagement builds more effective organisations. Schaufeli and Enzman (1998) partly agree with Maslach and Leiter's description, but in a different perspective define and operationalise work engagement in its own right. Schaufeli (2004) considers burnout and work engagement to be opposite concepts that should be measured independently with different instruments.

Job resources may also play an extrinsic motivational role because, according to the so-called "effort-recovery model" (Schaufeli \& Bakker, 2004), work environments that offer many resources foster the willingness to dedicate one's efforts and abilities to the work task. The outcome, be it through satisfaction of basic needs or the achievement of work goals, is positive and work engagement (a fulfilling, positive work-related state of mind) is likely to occur (Schaufeli \& Bakker, 2004).

In a South African study among teachers in the North West Province, Jackson (2004) confirmed that favourable job resources predict work engagement. Furthermore, he found that work engagement mediates the relationship between job resources and organisational commitment. The results were similar to those in a study among emergency workers in Gauteng (Naudé \& Rothmann, 2003). 
Engagement is also described as an evidence-based human resource management strategy to reduce turnover (Allen, Bryant, \& Vardaman, 2010) because it increases meaningfulness, autonomy, variety and valued job resources that enhance learning, growth and development (Houkes, Janssen, De Jonge, \& Nijhuis, 2001).

\subsection{Aetiology of work engagement}

Because aetiology deals with the philosophy of causation, an attempt will be made to assign causes or find reasons for the occurrence of work engagement in employees. Firstly, at individual level, Schaufeli and Bakker (2001) theorise that work engagement might be associated with underlying personality traits in the individual. Engaged employees may possess an inborn high energy level (Rothmann, 2002), making them more susceptible to work engagement. Secondly, Schaufeli and Bakker (2006) highlight social support, such as that from co-workers and superiors, performance feedback and coaching as significant causes of work engagement in groups. Thirdly, at organisational level, Schaufeli (2004) states that work engagement is related to job resources (as confirmed by Jackson, 2004), positive organisational attitudes, mental health, academic performance and self-efficacy, leading to an upward gain spiral. Job autonomy, task variety and the availability of training resources are other possible causes of work engagement (Demerouti et al., 2001). Sonnentag (2003) has proved that work engagement is positively related to the extent to which employees recover from their previous work day. Various reviews of the current research results (Christian, Garza, \& Slaughter, 2011; Crawford, LePine, \& Rich, 2010; Halbesleben, 2010; Schaufeli, 2012) have categorised the antecedents of work engagement as job resources (job control, social support, performance feedback, opportunities for training and development, task variety, responsibility, transformational leadership and organisational justice) and challenging job demands (workload, time urgency and mental demands).

A model for work engagement would thus include job resources and challenging demands, mediated by personal resources, leading to work engagement (Bakker \& Demerouti, 2008).

\subsection{Profile of an engaged employee}

Schaufeli and Bakker (2003) conclude from a number of interviews that typical "engaged workers" have a sense of energetic and effective connection with their work activities and see themselves as being able to deal with the demands of their job. Furthermore, typical engaged employees have the following characteristics: (1) They are active agents. Engaged employees take the initiative and give direction to their lives. Engaged employees are optimistic and trust themselves, characteristics which seem to overlap with what other have researchers called "personal initiative" or the "proactive personality" (Crant, 2000; Rothmann, 2002; Schaufeli, 2004). (2) They generate their own positive feedback. Engaged workers generate their own positive feedback. They create "rewards" in the form of recognition, success, administration and appreciation through their attitudes and activities. A positive spiral is thus maintained (Jackson, 2004). (3) They are also engaged outside their work. Engaged employees are characterised by energy and enthusiasm, both in their work and private lives - they have a type of energy that never seems to fade (Schaufeli \& Bakker, 2001). (4) They have values that match the organisation's values. Engaged employees' norms and values correspond with those of their organisation. If these goals are reached, employees experience meaning through their work (Jackson, 2004). (5) They sometimes feel tired as well. Compared with burnt-out employees, engaged employees experience a different type of exhaustion. Engaged employees experience exhaustion because their energy reserves are also limited. However, the exhaustion can be described as "exhausted but satisfied" (Schaufeli \& Bakker, 2001). (7)They want to work less, but they are not "workaholics". Engaged employees are not workaholics. They experience pleasure in their work and also enjoy hobbies and voluntary work in the community. In contrast, workaholics give the impression of being stressed and compulsive (Schaufeli \& Bakker, 2001).

The purpose of this paper is to review the manifestation of work engagement in female academics at two universities (an ODL and a traditional contact university) in South Africa.

\subsection{Hypotheses}

Based on the theoretical framework presented, the following hypotheses were formulated:

$\mathrm{H}_{01}$ : Female academics do not present with significant levels of work engagement (as represented by the subdimensions of vigour, dedication and absorption) at two universities in South Africa.

$\mathrm{H}_{\mathrm{a} 1}$ : Female academics present with significant levels of work engagement (as represented by the sub-dimensions of vigour, dedication and absorption) at two universities in South Africa. 
$\mathrm{H}_{02}$ : Differences do not exist in work engagement of female academics at two universities in South Africa in terms of biographical variables.

$\mathrm{H}_{22}$ : Differences do exist in work engagement of female academics at two universities in South Africa in terms of biographical variables.

\section{Research Methodology}

\subsection{Research design}

A quantitative cross-sectional survey design was used, measuring the research construct and sub-dimensions of the construct and reporting on the statistical correlation between them (Shaughnessy \& Zechmeister, 1997).

\subsection{Participants}

The population consisted of the female academics permanently employed at an ODL university and a contact university in the greater Tshwane region, Gauteng, South Africa. The entire population of 990 was invited to participate. Of the responses received, 187 were usable, resulting in a response rate of $18,9 \%$.

The biographical variables of the sample were as follows: females, ranging in age from 32 to 52 years old with an average of 9,5 years' work experience. The ODL university represented $55 \%$ and the contact university $45 \%$ of the participants. Of the respondents, $88 \%$ were white, $10 \%$ were black and $2 \%$ were from the Asian and coloured groups. A total of $65 \%$ of the respondents were married, $19 \%$ were single and $9 \%$ divorced. The "living together", "separated" and "widowed" categories were significantly smaller. In terms of their highest level of completed qualification, $6 \%$ had a national diploma or bachelor's degree $(M+3), 27 \%$ a BTech or honours degree $(M+4), 37 \%$ a master's degree $(M+5)$ and $30 \%$ a doctoral degree. The majority of respondents were lecturers or researchers (41\%), senior lecturers (23\%) and junior lecturers, researchers or research assistants (12\%). Professors (6\%) and associate professors (3\%) also represented significant groups within the sample.

\subsection{Instrument}

The measuring instrument consisted of a biographical questionnaire and the Utrecht Work Engagement Scale (UWES) (to measure the levels of work engagement). The UWES consists of 17 items and is scored on a 7-point frequency rating scale, ranging from 0 (never) to 6 (always) (Schaufeli \& Bakker, 2006). Three dimensions of the work engagement construct, namely vigour, dedication and absorption, were measured.

\section{Findings and Discussion}

The statistical analysis was conducted with the SSPS computer package (2001). Cronbach's alpha was calculated for the sub-dimensions of the UWES. A Cronbach's alpha of 0,7 or more is an indication of a reliable scale (Nunnally \& Bernstein, 1994; Pallant, 2001). Regarding Cronbach's alpha of the UWES, vigour was slightly below the 0,7 mark. The other dimensions scored from 0,75 to 0,87 ( table 1 ).

Table 1: Cronbach's alpha, means and standard deviations of the UWES ( $N=187)$

\begin{tabular}{|l|c|c|c|c|}
\hline \multicolumn{1}{|c|}{ Scale } & N of items & M & SD & A \\
\hline Total work engagement & 17 & 4,11 & 0,98 & 0,87 \\
Vigour & 6 & 4,18 & 1,0 & 0,64 \\
Dedication & 5 & 4,12 & 1,2 & 0,83 \\
Absorption & 6 & 4,19 & 1,03 & 0,75 \\
\hline
\end{tabular}

Based on these results it was decided to retain the construct, with all its respective sub-dimensions.

\subsection{Validity}

Exploratory and confirmatory factor analysis was performed. To examine the validity of the UWES, an exploratory factor 
analysis method was used to test each of the three scales individually, to confirm the validity of the factor structure of each of the scales within the sample. The results of the principal axis factor analysis support the three-factor solution found in previous studies, thus supporting the validity of the scale. Principal axis factor analysis with a direct oblimin rotation was used to investigate whether the factor structures of the three instruments could be replicated according to theoretical analysis. Prior to performing the factor analysis, the suitability of the data for factor analysis was assessed. The correlation matrices of each of the three instruments revealed a number of coefficients of 0,3 and above. The KaiserMayer-Olkin value exceeded the recommended value of 0,6 (Pallant, 2001) $(0,93)$. Bartlett's test of sphericity was statistically significant $(p=0,000)$ and the sample size was greater than the recommended 150 respondents $(n=187)$ (Pallant, 2001). The data was therefore considered suitable for factor analysis.

The factor structure of the UWES (table 2) presents the data after extraction for the three-factor solution to the UWES.

Table 2: Total variance explained for the overall scale of the UWES after extraction (excluding factors with eigenvalues<1)

\begin{tabular}{|c|ccc|ccc|c|}
\hline Factor & \multicolumn{3}{|c|}{ Initial Eigenvalues } & \multicolumn{3}{c|}{ Extraction Sums of Squared Loadings } & Rotation Sums of Squared Loadings (a) \\
\hline & Total & $\begin{array}{c}\% \text { of } \\
\text { Variance }\end{array}$ & $\begin{array}{c}\text { Cumulative } \\
\text { Percentage }\end{array}$ & Total & $\begin{array}{c}\text { \% of } \\
\text { Variance }\end{array}$ & $\begin{array}{c}\text { Cumulative } \\
\text { Percentage }\end{array}$ & Total \\
\hline 1 & 7,327 & 45,792 & 45,792 & 6,948 & 43,423 & 43,423 & 6,172 \\
2 & 1,542 & 9,636 & 55,428 & 1,083 & 6,768 & 50,192 & 2,902 \\
3 & 1,036 & 6,475 & 61,903 & 0,472 & 2,949 & 53,141 & 4,138 \\
\hline
\end{tabular}

A rotated pattern matrix was performed on the UWES. There were no items with factor loadings less than 0,3 on all factors, and therefore all items were retained for further analysis. Three clear factors emerged. Although three factors emerged, as suggested by the theory, these items do not correspond perfectly to the items defined by Schaufeli and Bakker (2006) as belonging to each of the questionnaire sub-dimensions. Factor 1 has the most items loading on the scale and accounts for the most variance (6\%) after rotation of the factors. The second factor, which also has a number of strong items loading on the factor, accounted for $3 \%$ of the total variance. Factor 3 accounts for $4 \%$ of the variance.

After the exploratory analysis, confirmatory factor analysis was also performed on the UWES. Confirmatory factor analysis seeks to determine if the number of factors and the loadings of measured (indicator) variables on them conform to what is expected on the basis of pre-established theory (Garson, 1998). The root mean square error of approximation (RMSEA), Hoelter index, Bentler burnoutnett index, as well as the Tucker Lewis index were used to determine the goodness-of-fit. All goodness-of-fit indicators for the UWES were found to be poor.

\subsection{Biographical variables}

The correlation between age and the total work engagement score, as well as all the sub-dimensions, were positive. This means that the older the female academic, the higher her scores on work engagement and hence vigour and absorption will be. It should be noted that although these correlations were significant, the size of the r-value (size of the correlation) was small.

The female academics with varying years of experience did not present with different work engagement scores. This means that work engagement was not associated with how long or short a female academic had been working for the HE institution.

The female academics from different population groups did not demonstrate different work engagement patterns, implying that members of the white, black, coloured and Asian population groups did not present with different work engagement scores.

No significant differences were found on the total scale or sub-dimensions of the UWES between the three groups. Females who were single, married, living together, separated or widowed did not present with different work engagement scores.

Regarding the level of education, only one statistically significant difference between the four groups presented at the $p<0,05$ level on the vigour sub-scale of the UWES $[F(3,183)=2,96 ; p=0,03]$. Post hoc comparisons using the Tukey HSD test indicated that the mean score for respondents with a master's degree $(M=19,14 ; S D=4,79)$ was significantly different from respondents with a doctoral degree $(M=21,65$; $S D=5,37)$. The implication is that female academics that have completed their doctoral degree are significantly more energetic, resilient while working and willing to invest time in 
their work even in the face of difficulty.

Table 3: Total variance explained for the overall scale of the UWES before extraction (excluding factors with eigenvalues lower than 1)

\begin{tabular}{|c|ccc|ccc|c|}
\hline Factor & \multicolumn{4}{|c|}{ Initial Eigenvalues } & \multicolumn{3}{c|}{ Extraction Sums of Squared Loadings } \\
\hline & Total & \% of Variance & Cumulative Percentage & Total & $\%$ of Variance & Cumulative Percentage \\
\hline 1 & 7,33 & 45,79 & 45,79 & 6,95 & 43,42 & 43,42 \\
2 & 1,54 & 9,64 & 55,43 & 1,08 & 6,77 & 50,19 \\
3 & 1,04 & 6,48 & 61,90 & 0,47 & 2,95 & 53,14 \\
\hline
\end{tabular}

Table 4: Total variance explained for the overall scale of the UWES after extraction (excluding factors with eigenvalues lower than 1)

\begin{tabular}{|c|c|c|c|c|c|c|c|}
\hline Factor & \multicolumn{3}{|c|}{ Initial Eigenvalues } & \multicolumn{3}{|c|}{ Extraction Sums of Squared Loadings } & Rotation Sums of Squared Loadings (a) \\
\hline & Total & $\begin{array}{c}\text { \% of } \\
\text { Variance }\end{array}$ & $\begin{array}{c}\text { Cumulative } \\
\text { Percentage }\end{array}$ & Total & $\begin{array}{c}\text { \% of } \\
\text { Variance }\end{array}$ & $\begin{array}{c}\text { Cumulative } \\
\text { Percentage }\end{array}$ & Total \\
\hline 1 & 7,327 & 45,792 & 45,792 & 6,948 & 43,423 & 43,423 & 6,172 \\
2 & 1,542 & 9,636 & 55,428 & 1,083 & 6,768 & 50,192 & 2,902 \\
3 & 1,036 & 6,475 & 61,903 & 0,472 & 2,949 & 53,141 & 4,138 \\
\hline
\end{tabular}

Extraction method: principal axis factoring

a When factors are correlated, sums of squared loadings cannot be added to obtain a total variance.

Examining the factor matrix after the three factors were extracted did not reveal a simple structure. Items loaded on more than one factor. The majority of the items, however, did load strongly on the first factor.

Table 5: Pattern matrix for the three-factor solution of the UWES

\begin{tabular}{|l|c|c|c|}
\hline Item numbers & Factor 1 & Factor 2 & Factor 3 \\
\hline Question 2,5 & 0,863 & 0,023 & 0,009 \\
Question 2,7 & 0,832 & 0,061 & $-0,114$ \\
Question 2,8 & 0,776 & 0,039 & $-0,036$ \\
Question 2,2 & 0,770 & $-0,034$ & $-0,179$ \\
Question 2,1 & 0,703 & $-0,082$ & $-0,106$ \\
Question 2,4 & 0,651 & $-0,023$ & 0,190 \\
Question 2,9 & 0,583 & 0,095 & $-0,150$ \\
Question 2,3 & 0,375 & 0,087 & $-0,076$ \\
Question 2,13 & 0,321 & 0,219 & $-0,254$ \\
Question 2,16 & 0,092 & 0,722 & 0,146 \\
Question 2,14 & 0,372 & 0,453 & $-0,281$ \\
Question 2,6 & 0,235 & 0,266 & $-0,228$ \\
Question 2,17 & $-0,036$ & 0,251 & $-0,061$ \\
Question 2,11 & 0,215 & 0,110 & $-0,647$ \\
Question 2,10 & 0,268 & $-0,124$ & $-0,646$ \\
Question 2,12 & $-0,087$ & 0,329 & $-0,608$ \\
\hline
\end{tabular}

Because two biographical variables (age and having a doctoral degree) correlated significantly positively with some of the work engagement dimensions, these correlations are represented graphically in figure 1.

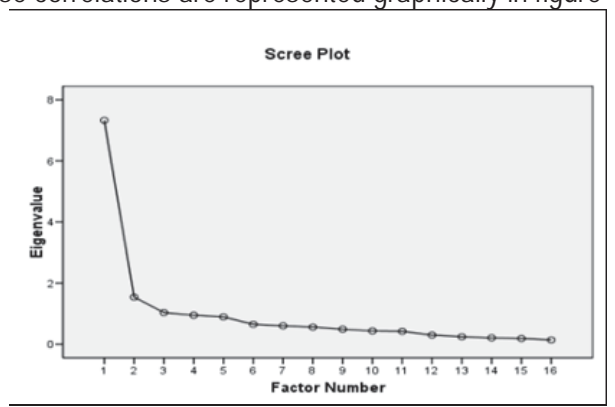

Figure 1: Scree plot for the overall scale of the UWES 


\section{Discussion}

In terms of the manifestation of work engagement in the sample of female academics, measured against the norms provided by Schaufeli and Bakker (2006), the score for the total work engagement construct was moderate. In addition, scores on the three sub-dimensions of vigour, dedication and absorption were all just above average, indicating a moderately positive trend. Female academics are thus in general fairly energetic, mentally resilient, strongly involved in their jobs, enthusiastic, proud, inspired and happily engrossed in their work. It can thus be concluded that the empirical evidence provided moderate support for the first hypothesis.

The changing world of work, as reviewed by Stanz (2013) and Furnham (2013), is also reflected in the changes to the job expectations of female academics. If the characteristics identified by Stanz (2013) are considered, relevant themes include globalisation of the HE system, digital transformation in both contact and distance learning institutions, academics working remotely via learning management systems, the shortage of academics with doctoral degrees and the increased use of social media in education. Additional challenges that contribute to the complexity of the environment include a very high student to lecturer ratio in developing countries, an unrealistically high student to postgraduate supervisor ratio, decreasing resources and increasing demands by faculty, students and parents. As a consequence of the increasing digitisation, the "distance" between lecturer and student is increasing, resulting in feelings of isolation and loneliness on both sides. Furthermore, the lines between work time and personal time are increasingly blurred. Students expect immediate and constant feedback to their questions in an online environment.

Furthermore, pressure to increase research outputs, exhausting interpersonal relationships with students and escalating administrative duties exacerbate the problem. Considering the above, the role of organisational psychologists (Furnham, 2013) in the future in supporting academics to adjust and cope with the demands of their changing role should be emphasised. In addition, the exploration of positive psychological constructs (Breed et al., 2006), such as work engagement, to understand why some people cope well with the rapidly changing world of work can make a valuable contribution to our understanding of the phenomenon.

Jamlan (2004) emphasises the importance of academics accepting responsibility for their own career development. It is therefore increasingly necessary for the female academic to take the initiative in managing her own work situation to such an extent that she can remain happily engrossed, inspired and engaged by her job (Crant, 2000). In keeping with Jamlan's recommendation, allowing for and encouraging professional development through mentoring, coaching and networking will nurture a sense of accomplishment and contribute to a fully developed professional identity in the academic. Support programmes in which academics are taught how to depersonalise incidents is strongly suggested.

In terms of hypothesis two, referring to the demographical data, a positive relationship was found between the age of the female academic and her scores on the vigour and absorption sub-dimensions. This implies that the older the female academic, the higher her scores on vigour and absorption will be. This is in accordance with the findings of Schaufeli (2004) and Wissing and Van Eeden (2002). Labour market trends indicate that older workers play an increasingly important role in the workforce today (Eichar, Norland, Brady, \& Fortinsky, 1991; Theodore \& Lloyd, 2000). The work orientation of older female academics is thus of theoretical and practical interest. Clark, Oswald and Warr (1996) report higher levels of job satisfaction in workers over 40 and suggest that this is because of increased coping capacity, greater stability and ego strength with age. Theodore and Lloyd (2000) found that as workers age, they become more inwardly focused and invest their efforts in the enjoyment of the process, the quality of the experience and emotional connectedness. Oshagbemi (1997) also found that women tend to be slightly more satisfied with their academic careers after the age of 45 than their male colleagues.

Regarding the highest level of completed qualifications, significant differences were found in one of the dimensions of work engagement, namely vigour. Academics with a doctoral degree scored significantly higher than respondents with a master's degree. As academics with a doctoral degree typically are employed at senior lecturer and higher organisational level, it may also imply that being in possession of a doctoral degree and being employed at a higher organisational level are associated with higher levels of vigour. Tytherleigh (2003) argues that the levels of occupational stress reported by women working in higher education are contingent on job-related factors, for example seniority.

It is noteworthy that the nature of the academic job complicates social support from colleagues, because by its very nature, it is an independent and autonomous job. It is arguably even more difficult in an ODL context to create and maintain social bonds, as the accepted form of communication in this context is virtually, via the learning platform of the specific institution (Bezuidenhout, 2013). Therefore it is strongly recommended that management create structured opportunities for interaction among academic staff members in the form of informal teabreaks or more structured discussion forums on various topics such as teaching and learning, research and community engagement.

On the positive side, the digitisation of the academic job greatly enhances the opportunities to restructure the job, 
increasing flexibility. As it is perfectly suited to a "working remotely" scenario, this could be used to address the role conflict that female academics continuously face.

From a positive psychological and preventive point of view, the focus should be on interventions that will contribute to a situation of a "good fit" between the female and her academic job in the tertiary institution. In terms of organisational strategies to foster the experience of work engagement in this target group, a workload strategy should be formulated that includes appropriate objectives for being more resilient, having uninterrupted and dedicated research time, improved time management and a reduced workload.

Studies on the manifestation of work engagement, specifically in females, are rare. The construct of work engagement, together with its measuring instrument, the UWES, is a fairly recently developed construct, which made it challenging to find comparable research results. The fact that a cross-sectional design was used creates a limitation in terms of solving cause and effect issues, and longitudinal studies are recommended. The relatively small sample size (187 respondents) implies that caution should be exercised when generalising. The study relies exclusively on self-report measures. Only one psychometric instrument was used and no objective indicators, for example actual turnover, were included.

\section{Concluding Remarks}

To conclude, this article has demonstrated that extensive research is needed on the manifestation of work engagement, specifically on the female gender in higher education institutions. By focusing on engagement with the future world of work, it is hoped that these institutions, female academics and ultimately society at large will benefit from quality teaching, learning, research and community engagement.

\section{References}

Allen, D.G., Bryant, P.C. \& Vardaman, J.M. (2010). Retaining talent: Replacing misconceptions with evidence-based strategies. Academy of Management Perspectives, May, 48-64.

Bakker, A.B. \& Demerouti, E. (2008). Towards a model of work engagement. Career Development International, 13, 209-223.

Bakker, A.B., Demerouti, E. \& Schaufeli, W.B. (2005). The crossover of burnout and work engagement among working couples. Human Relations, 58(5), 661-689.

Bezuidenhout, A. (2013). The changing role of the ODL academic: An auto-ethnographical account. Progressio, 35(2), 19-33.

Bezuidenhout, G., De Jager, J. \& Naidoo, V. (2013). Factors that influence the choice of private higher education institutions by students. South African Journal of Higher Education, 27(5), 1181-1196.

Blix, A.G., Cruise, C.J., Mitchell, B.M. \& Blix, G.G. (1994). Occupational stress among university teachers. Educational Research, 36, 157-169.

Breed, M., Cilliers, F. \& Visser, D. (2006). The factor structure of six salutogenic constructs. South African Journal of Industrial Psychology, 32(1), 74-87.

Christian, M.S., Garza, A.S. \& Slaughter, J.E. (2011). Work engagement: A quantitative review and test of its relations with task and contextual performance. Personnel Psychology, 64, 89-136.

Clark, A., Oswald, A. \& Warr, P. (1996). Is job satisfaction U-shaped in age? Journal of Occupational and Organisational Psychology, 69(1), 57-81.

Crant, J. (2000). Proactive behaviour in organisations. Journal of Management, 26, 435-462.

Crawford, E.R., LePine, J.A. \& Rich, B. (2010). Linking job demands and resources to employee engagement and burnout: A theoretical extension and meta-analytic test. Journal of Applied Psychology, 95, 834-848. doi:10.1037/a0019364

Csikszentmihalyi, M. (1990). Flow: The psychology of optimal experience. New York: Harper \& Row.

Demerouti, E., Bakker, A.B., De Jonge, J., Janssen, P.P.M. \& Schaufeli, W.B. (2001). Burnout and engagement at work as a function of demands and control. Scandinavian Journal of Work Environment Health, 27(4), 279-286.

Diener, E., Suh, E.M., Lucas, R.E. \& Smith, H.I. (1999) Subjective well-being: Three decades of progress. Psychological Bulletin, 125, 267-302.

Eichar, D.M., Norland, S., Brady, M.E. \& Fortinsky, R.H. (1991). The job satisfaction of older workers. Journal of Organisational Behaviour, 12, 609-20.

Furnham, A. (2013). More is nog ' $n$ dag [Tomorrow is another day]: The new world of work. Presentation at $15^{\text {th }}$ Annual Siopsa Conference, 29-31 July 2013, CSIR, Pretoria.

Garson, G.D. (1998). Factor analysis: Stat notes, from North Carolina State University, Public Administration Programme. North Carolina State University [Online] Available: http://www2.chass.ncsu.edu/garson/ pa765/factor.htm (November 11, 2013).

Gonzalez-Roma, V., Schaufeli, W.B., Bakker, A.B. \& Lloret, S. (2006). Burnout and work-engagement: Independent factors or opposite poles? Journal of Vocational Behaviour, 68, 165-174.

Halbesleben, J.R.B. (2010). Organizational concern, prosocial values, or impression management? How supervisors attribute motives to 
organizational citizenship behavior. Journal of Applied Social Psychology, 23(6), 925-1489.

Houkes, I., Janssen, P.P.M., De Jonge, J. \& Nijhuis, F.J.N. (2001). Specific relationships between work characteristics and intrinsic motivation, burnout and turnover intention: A multi-sample analysis. European Journal of Work and Organisational Psychology, 10, 1-23.

Jackson, L.T.B. (2004). Burnout and engagement of teachers in the North West Province. Unpublished doctoral dissertation. North-West University, Potchefstroom.

Jamlan, M. (2004). Faculty opinions towards introducing e-learning at the University of Bahrain. International Review of Research in Open Distance Learning, 5(2).

Langelaan, S., Bakker, A.B., Van Doornen, L.J.P. \& Schaufeli, W.B. (2006). Burnout and work engagement: Do individual differences make a difference? Personality and Individual Differences, 40, 521-532.

Maslach, C. \& Leiter, M.P. (1997). The truth about burnout. San Francisco: Wiley.

Naudé, J.L.P. \& Rothmann, S. (2003). The validation of the Maslach burnout inventory: Human sciences survey for emergency workers in Gauteng. Paper presented at the $6^{\text {th }}$ Annual Conference of the Society for Industrial/Organisational Psychology, Johannesburg.

Nelson, D.L., Burke, R.J. \& Michie, S. (2002). New directions for studying gender, work stress and health. In D.L. Nelson \& R.J. Burke (Eds.), Gender workstress and health (pp. 229-239). Washington DC: American Psychological Association.

Nunnally, J. \& Bernstein, I.H. (1994). Psychometric theory (3rd ed.). New York: McGraw-Hill.

Nzimande, B. (2014). White Paper on Post Secondary Education in South Africa speech. Retrieved 24 January, 2014 from http://mg.co.za/article/2014-01-16-blade-launches-dhets-white-paper-to-meet-needs-of-the-neets.

Oshagbemi, T. (1997). Job satisfaction profiles of university teachers. Journal of Managerial Psychology, 12(1), 27-39.

Pallant, J. (2001). SPSS survival manual. New York: McGraw-Hill.

Rothmann, S. (2002, November). Burnout and engagement: A fortigenic perspective. Inaugural lecture. Potchefstroom University for Christian Higher Education, South Africa.

Schaufeli, W.B. (2004, March). Burnout and engagement. Paper presented at the $2^{\text {nd }}$ South African Work Wellness Conference, Potchefstroom, South Africa.

Schaufeli, W.B. (2012). Work engagement: A useful construct for research and practice? Paper presented at the 10 $10^{\text {th }}$ European Academy of Occupational Health Psychology, Zurich, Switzerland.

Schaufeli, W.B. \& Bakker, A.B. (2001). Job demands, job resources and their relationship with burnout and engagement: A multi-sample study on the COBE-model. Utrecht: Utrecht University, Psychology \& Health.

Schaufeli, W.B. \& Bakker, A.B. (2003). Utrecht work engagement scale: Preliminary manual. Utrecht: Utrecht University.

Schaufeli, W.B. \& Bakker, A.B. (2004). Job demands, job resources and their relationship with burnout and engagement: A multi-sample study. Journal of Organisational Behaviour, 25, 293-315.

Schaufeli, W.B. \& Bakker, A.B. (2006). The measurement of work engagement with a short questionnaire. Educational and Psychological Measurement, 66(4), 701-716.

Schaufeli, W.B. \& Enzman, D. (1998). The burnout companion to study and practice: A critical analysis. London: Taylor \& Francis.

Seligman, M.E.P. (2002). Authentic happiness: Using the new positive psychology to realize your potential for lasting fulfillment. New York, NY: Free Press.

Shaughnessy, J.J. \& Zechmeister, E.B. (1997). Research methods in psychology (4th ed.). New York: McGraw-Hill.

Simmons, B.L. (2000). Eustress at work: Accentuating the positive. Unpublished doctoral dissertation. Oklahoma State University.

Siopsa. (2013). Making a difference in the future world of work. 15 th Annual Siopsa Conference, 29-31 July 2013, CSIR, Pretoria.

Sonnentag, S. (2003). Recovery, work engagement, and proactive behaviour: A new look at the interface between non-work and work. Journal of Applied Psychology, 88, 518-528.

Stanz, K. (2013). Presidential address and welcome. 15th Annual Siopsa Conference, 29-31 July 2013, CSIR, Pretoria.

Storm, K. (2002). Burnout and work engagement in the South African Police Service. Unpublished doctoral dissertation. North-West University, Potchefstroom.

Taylor, S.E., Klein, L.C., Lewis, B.P., Grunewald, T.L., Gurung, R.A. \& Updegraff, J.A. (2000). Biobehavioural responses to stress in females: Tend-and-befriend, not fight-or-flight. Psychological Review, 107, 411-429.

Theodore, H. \& Lloyd, B.F. (2000). Age and gender role conflict: A cross-sectional study of Australian men. Sex Roles, 42(11/12), 10271042.

Tytherleigh, M.Y. (2003). What employers may learn from English higher education institutions: A fortigenic approach to occupational stress. South African Journal of Industrial Psychology, 29(4).

Wissing, M.P. \& Van Eeden, C. (2002). Empirical classification of the nature of psychological well-being. South African Journal of Psychology, 32, 32-44. 